\title{
MOLECULAR CHARACTERIZATION OF MYCOBACTERIUM AVIUM SUBSP. PARATUBERCULOSIS ISOLATES
}

\author{
SOBHA RANI M*, PRABHAKAR TG ${ }^{2}$, SAMUEL MASILMONI RONALD B ${ }^{2}$ \\ ${ }^{1}$ Department of Sero-epidemiology, Southern Regional Disease Diagnostic Laboratory, Institute of Animal Health and Veterinary \\ Biological, Hebbal, Bengaluru, Karnataka, India. ${ }^{2}$ Department of Veterinary Microbiology, Madras Veterinary College, Chennai, Tamil \\ Nadu, India. Email: sobha.m.rani@gmail.com
}

Received: 27 January 2017, Revised and Accepted: 03 March 2017

ABSTRACT

Objective: Johne's disease, caused by Mycobacterium avium subsp. paratuberculosis (MAP), is highly prevalent in domestic ruminants. In India, the exact prevalence of MAP genotypes still remains unknown limited, and the systematic disease control programs are also limited. This study was undertaken to study the molecular characterization of MAP isolates.

Methods: About 22 MAP isolates were from cattle, sheep, and goat under gone the molecular characterization by three different methods (1) IS1311 polymerase chain reaction (PCR) with restriction enzyme analysis (REA), (2) GyrA and GyrB PCR with sequencing, and (3) digital microfluidic chip (DMC)-PCR. The study demonstrated that a) IS1311 PCR with REA (based on point mutations) identified all 22 MAP isolates as "intermediate type" irrespective of a host of origin and also belong to Indian Bison type. Molecular typing based on the gyrA and gyrB genes partial amplification and sequencing revealed that the MAP isolates exhibited more lineages toward the reference Type III, Intermediate strain.

Results: The MAP isolate of sheep origin showed more lineages toward the sheep type than the isolates of cattle and goats. This variation may be due to host-pathogen interactions and adaptation to different hosts and environmental conditions in the nature.

Conclusions: The DMC-PCR, which is based on sequence difference at 5 `end of IS900 of MAP, differentiated rapidly all the isolates as sheep type. The application of DMC-PCR to differentiate sheep and Intermediate types is limited as the Intermediate type (Type III) and sheep type (Type I) are very closely related to each other and all the MAP isolates were confirmed as Intermediate or Type III by three different methods which are commonly present in India, Spain, and Iceland.

Keywords: Johne's disease, Mycobacterium avium subsp. paratuberculosis, Polymerase chain reaction, Digital microfluidic chip-polymerase chain reaction.

(C) 2017 The Authors. Published by Innovare Academic Sciences Pvt Ltd. This is an open access article under the CC BY license (http://creativecommons. org/licenses/by/4. 0/) DOI: http://dx.doi.org/10.22159/ajpcr.2017.v10i5.17310

\section{INTRODUCTION}

Johne's disease (JD), caused by Mycobacterium avium subsp. paratuberculosis (MAP) is a debilitating chronic and progressive infectious enteritis in a wide range of domestic and wild animals [1]. It is a member of $M$. avium intracellulare complex including $M$. avium subsp. avium, MAP, M. intracellulare, and Mycobacterium silvaticum are more closely related genetically at nucleotide level. However, differ widely in terms of phenotype, microbiological characters, pathogenicity, disease, and host specificity.

National Animal Health monitoring system in the USA found out that $20-40 \%$ of the dairy herds had MAP infection with huge economic losses [2]. Similar prevalence rates have been found in England and other European countries. Detection of the pathogen by isolating the organism by fecal culture is the gold standard for the diagnosis of JD [3]. However, slow growth and fastidious nature of the organism are of great impediments for regular culture test; however, discovery of $M$. avium complex insertion sequences, present in multiple copies provided a simple approach for characterizing the isolates of M. avium complex. The first insertion sequence, IS900 identified [4] was found to be unique to MAP isolates of both animals and humans, was exploited to develop a polymerase chain reaction (PCR) for identification of MAP.

Strain identification is a useful tool in epidemiological investigation to gain a better understanding of the origin of infection, identification of risk factors that influence transmission, characterization of the pathogenesis and evaluation of existing control programs [5]. The molecular characterization of 22 MAP isolates of bovine, ovine, and caprine origin was characterized by three different methods (1) IS 1311 PCR with restriction enzyme analysis (REA), (2) GyrA and GyrB PCR with sequencing, and (3) digital microfluidic chip (DMC) PCR.

\section{MATERIALS AND METHODS}

\section{Source of MAP isolates}

A total of 22 MAP isolates collected from samples (dung and tissues) of cattle, sheep, and goat from farms with the previous history of JD and from suspected clinical cases at the Teaching Hospital, Madras Veterinary College (MVC), Chennai were utilized in the study. One reference vaccine strain-sheep type was maintained in Microbiology Department, MVC, Chennai as a reference standard. Before carrying out the molecular typing, genomic DNA was isolated as described by Reddy et al. 2014 [6], followed by amplification of IS900 gene and confirmed by F57 by PCR as described by Vansnick et al. (2004) [7] with modifications.

\section{Molecular typing of MAP isolates}

Molecular typing of 22 MAP isolates was carried out by three methods:

1. Insertion sequence IS1311 PCR (IS1311) with REA

2. GyrA and GyrB gene PCR with sequencing

3. D. M. Collins-PCR (Table 1).

Reagents and other consumables for PCR with REA

Restriction enzymes Hinf1 and MseI (New England Biolabs, England). Amplicons of IS1311 PCR. Buffers and Bovine serum albumin supplied along with enzymes. 
The amplification of IS1311 gene was carried out in automated thermal cycler with the following program: Denaturation: $95^{\circ} \mathrm{C}$ for 3 minutes; Annealing: $62^{\circ} \mathrm{C}$ for 15 seconds; Extension: $72^{\circ} \mathrm{C}$ for 1 minutes, followed by 35 cycles of amplification and the final elongation step $\left(72^{\circ} \mathrm{C}\right.$ for 7 minutes), PCR products of IS1311 were separated and analyzed on $1 \%$ agarose gel electrophoresis, along with the standard DNA ladder. Amplicons of IS1311 PCR were subjected to restriction analysis. The reaction mixture was incubated in a water bath at $37^{\circ} \mathrm{C}$ for $2 \mathrm{hrs}$ for digestion and enzyme activity was stopped by incubating at $100^{\circ} \mathrm{C}$ for 10 minutes. Digested products were electrophoresed in $1 \%$ agarose gel in TAE with DNA standard marker.

\section{GyrA and GyrB gene PCR with sequencing}

Five individual PCR reactions were conducted as described by Nath 2013 [8], using five sets of specific primers for gene fragments, GyrA (3 fragments) and GyrB (2 fragments) genes of MAP (Table 2).

Reaction mixture was prepared using the template DNA from culture isolates, specific primers in $10 \rho$ mol each along with master mix and made up to $25 \mu \mathrm{l}$ in $0.2 \mathrm{ml}$ PCR tubes. All the PCR tubes were centrifuged and transferred to automatic thermal cycler to carry out the PCR. The reaction mixture and reaction cycle conditions were same for both GyrA and GyrB genes except the gene fragment specific primers. Amplification of GyrA and GyrB genes of MAP was carried out as per the program as outlined as bellow: Denaturation: $95^{\circ} \mathrm{C}$ for 30 seconds; Annealing: $58.5^{\circ} \mathrm{C}$ for 15 seconds; Extension: $72^{\circ} \mathrm{C}$ for 1 minutes, followed by 35 cycles of amplification and the final elongation step $\left(72^{\circ} \mathrm{C}\right.$ for 10 minutes), PCR products of IS1311 were separated and analyzed on $1 \%$ agarose gel electrophoresis, along with the standard DNA ladder. Amplified products of GyrA and GyrB genes from five PCR reactions were gel purified and subjected to sequencing in automatic sequencer by BigDye termination chemistry using the PCR specific primers.

\section{DM Collins-PCR}

Reaction mixture was prepared using the template DNA from MAP culture isolates, to carry out the PCR (Table 3).
The DMC-PCR was carried out as per the following program as shown in the Scheme 1.

Purified products of IS1311PCR, gyrA and gyrB and DMC-PCR were subjected to sequencing in ABI automatic sequencer (ABI Prism, Applied Biosystems, USA) using BigDye termination chemistry with specific PCR primers. Sequences obtained were analyzed by BLAST search in NCBI and compared with available highly similar sequences in the GenBank. Multiple alignments of nucleotide sequence of partially amplified PCR products were done using ClustalW and BioEdit software. The phylogenetic tree was drawn using NeighborJoining method, and pair wise identity matrix was done by ClustalW and BioEdit software.

\section{RESULTS}

All the isolates generated MAP specific amplicons of 572 bp by the IS900 PCR as shown in Fig. 1.

All the positive isolates for IS900 PCR were amplified by F57 PCR. All the isolates generated 472 bp amplicon specific for F57 gene as shown in Fig. 2.

\section{IS 1311 PCR with REA}

All the isolates generated $604 \mathrm{bp}$ amplicon specific for IS1311 gene of MAP as shown in Fig. 3.

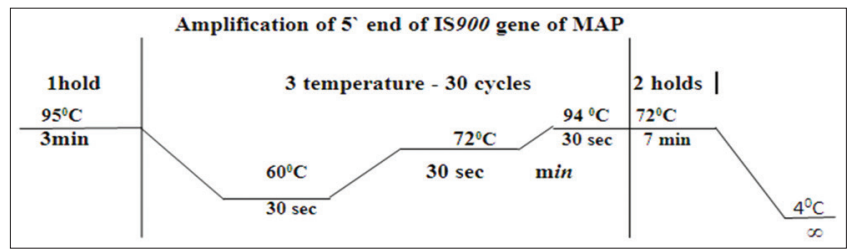

Scheme 1: Sequence analysis of 1311 polymerase chain reaction (PCR) with restriction enzyme analysis, gyr $A$ and $g y r B$ and digita microfluidic chip-PCR products

Table 1: IS1311 PCR with REA primers

\begin{tabular}{lll}
\hline Gene & Primers & Primer sequence \\
\hline IS1311 & Forward-M56 & 5`-GCG TGA GGC TCT GTG GTG AA-3` \\
& Reverse-M119 & 5`-ATG ACG ACC GCT TGG GAG AC-3` \\
\hline
\end{tabular}

PCR: Polymerase chain reaction, REA: Restriction enzyme analysis

Table 2: Details of primers for GyrA and GyrB PCR used for amplification of isolated DNA from culture isolates

\begin{tabular}{|c|c|c|c|}
\hline Gene & Primer & Primer sequence and position & Expected product size \\
\hline \multirow[t]{2}{*}{ Gyr A1 } & Forward & 5`CCATGT ACGACT CGG GTT TC-3` (176-195) & $746 \mathrm{bp}$ \\
\hline & Reverse & 5`-GGA ATTGGT CCT CGA TAT TGG-3` (902-921) & \\
\hline \multirow[t]{2}{*}{ Gyr A2 } & Forward & 5`-GGA GTC GTT GAG GTC TTG GTG-3`(766-785) & $841 \mathrm{bp}$ \\
\hline & Reverse & $5 `$ GGT ACA GGT CGG TCT TGG TG-3`(1587-1606) & \\
\hline \multirow[t]{2}{*}{ Gyr A3 } & Forward & 5`-ACG TCG TCG TCA CCA TCAC-3` (1547-1565) & $882 \mathrm{bp}$ \\
\hline & Reverse & 5`-CCT CAC CCA GAT TCA TCA GC-3` (2409-2428) & \\
\hline Gyr B1 & Forward & 5-'AAG AAG GCG CAA GAC GAA TA-3`(16-35) & $1001 \mathrm{bp}$ \\
\hline \multirow[t]{2}{*}{ Gyr B2 } & Forward & 5`-GTA CGC CAA GGA CAA GAA GC-3` (996-1016) & 897bp \\
\hline & Reverse & 5`-GTG GGA TCC ATT GTG GTT TC-3` (1873-1892) & \\
\hline
\end{tabular}

PCR: Polymerase chain reaction

Table 3: Details of primers used in DM Collins-PCR to amplify DNA from MAP isolates

\begin{tabular}{lll}
\hline Gene & Primer & Sequence \\
\hline IS900-5 end & DMC1-529 - Forward & 5' - GCT GTT GGC TGC GTC ATG AAG - 3' \\
& DMC1-531 - Forward & 5' - TCT TAT CGG ACT TCT TCT GGC - 3' \\
& DMC1-533 - Reverse & 5' - CGG ATT GAC CTG CGT TTC AC- 3' \\
\hline
\end{tabular}

MAP: Mycobacterium avium subsp, paratuberculosis, PCR: Polymerase chain reaction 
A total of 22 MAP isolates from cattle, sheep, and goats showed amplicons of specific to IS1311 and generated bands of $67 \mathrm{bp}, 218 \mathrm{bp}$, and 323 bp on Hinf1 and Mse1 digestion of IS1311 PCR products similar tor Intermediate type of MAP.

Nucleotide sequences of partially amplified IS1311 products of selected MAP isolates were analyzed and identified the MAP specific restriction enzyme Hinf1 site in the sequences using online software New India Biolabs (NIB) cutter. The restriction enzyme BSJ1 site, which is specific to Indian isolates of bison type, was also identified in the obtained sequences as shown in Fig. 4.

\section{Molecular typing by gyrA and gyrB PCR}

Amplification of gyr $A$ and gyr $B$ genes of all 24 MAP isolates generated $\operatorname{gyr} A(A 1, A 2$, and $A 3)$ and gyrB (B1 and B2) specific amplicons of $746 \mathrm{bp}$, 841 bp, 882 bp, 1001 bp, and 897 bp as shown in Fig. 5).

\section{Sequence analysis of amplicons of gyrA and gyrB PCR}

Phylogenetic analysis of nucleotide sequences of partially amplified gyrA (Fig. 6) and gyrB (Fig. 7) genes of three selected MAP isolates,

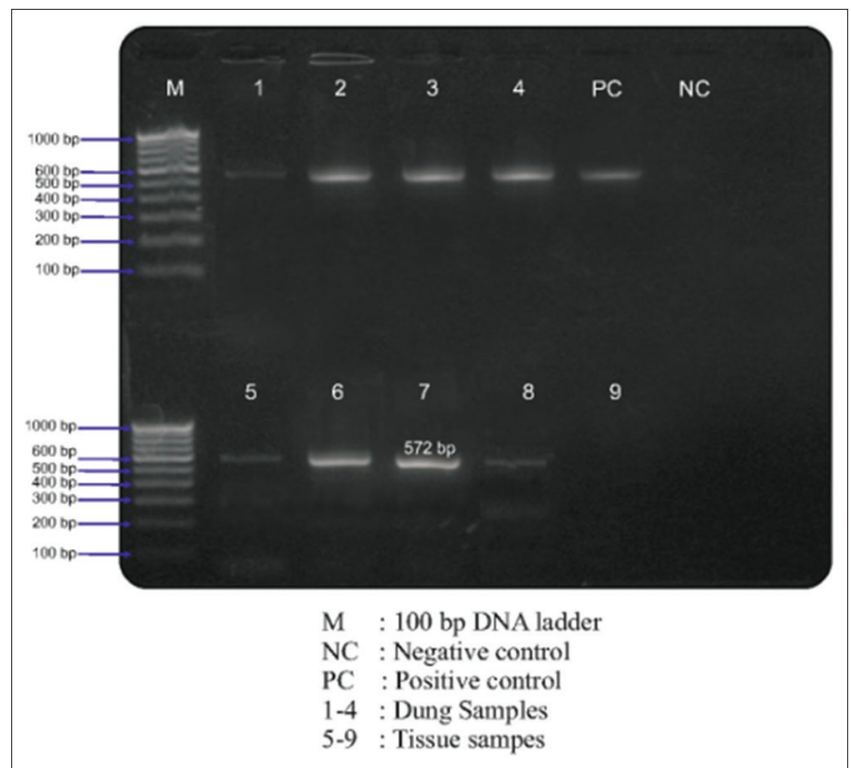

Fig. 1: Amplification of DNA of isolates by IS900 polymerase chain reaction

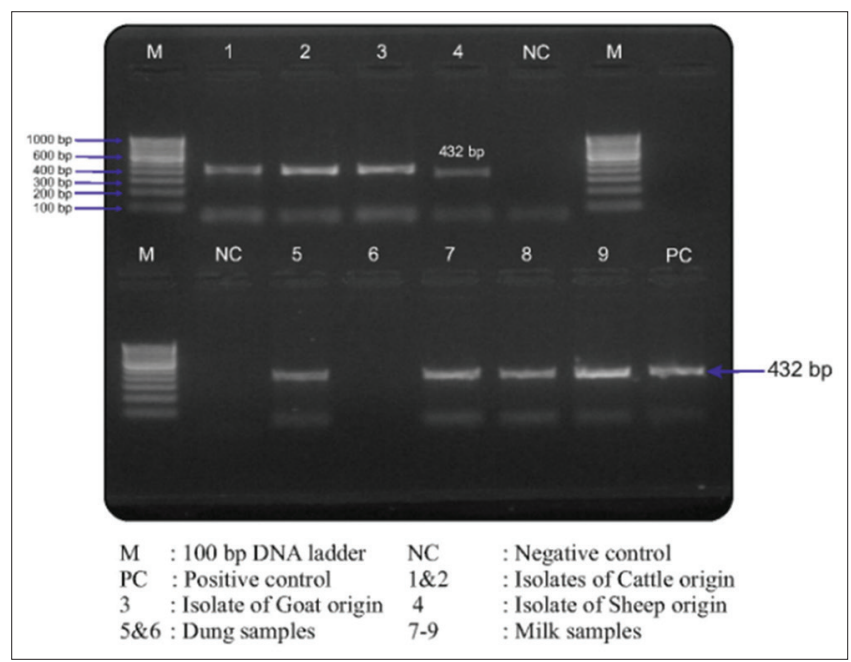

Fig. 2: Polymerase chain reaction amplification of F57 gene of Mycobacterium avium subsp. paratuberculosis isolates one each from cattle, sheep and goat were aligned with reference type strains (I, II and III) using CLUSTAL-W and phylogenetic tree was drawn using Neighbor-Joining UPGMA method.

The study revealed that the MAP isolates belong to the reference MAP type III (Intermediate type) irrespective of host of origin. On phylogenetic analysis of gyr genes, the isolate of sheep origin showed more lineages towards type III and the isolates of cattle and goat origin showed lineage between type III and II (MAP-K10).

\section{Molecular typing by DMC- PCR}

Amplification of $5^{\prime}$ end of IS900 of MAP isolates by DMC primers revealed amplicons of $162 \mathrm{bp}$ indicating that all the isolates belonged to the sheep lineage of MAP irrespective of the host of origin. All the isolates generated $162 \mathrm{bp}$ amplicon specific to sheep type irrespective of their host of origin by DMC-PCR and template DNA from Mycobacterium phlei did not generate any amplicon, when amplified by primers specific to $5{ }^{`}$ end of IS900 as shown in Fig. 8.

Thus, the results from this study confirmed that all the isolates studied were Type III or intermediate type, which were closely related to Type I isolates or sheep type irrespective of host of origin.

\section{DISCUSSION}

Lack of specific and rapid diagnostics are a great impediment in the control of Johne's disease and to monitor the existing control programs. To formulate strategies for control of the infection, a sheer necessity, the existing isolates were characterized by three different

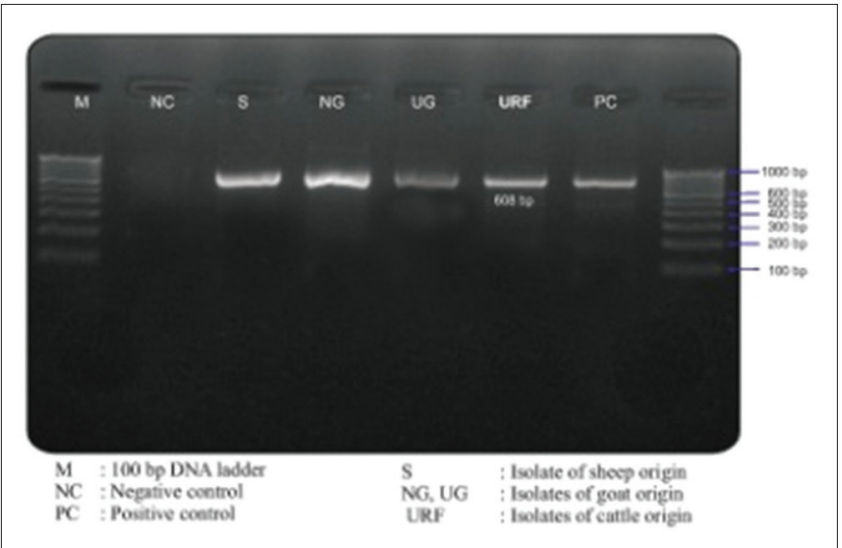

Fig. 3: Polymerase chain reaction amplification of IS1311 gene of Mycobacterium avium subsp. paratuberculosis isolates

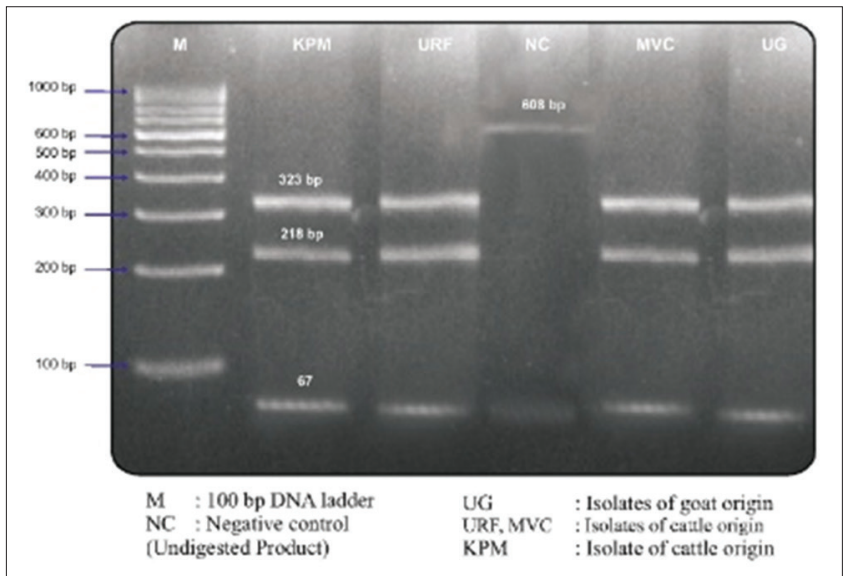

Fig. 4: Digestion of IS1311 polymerase chain reaction amplicons with Mse1 and Hinf1 


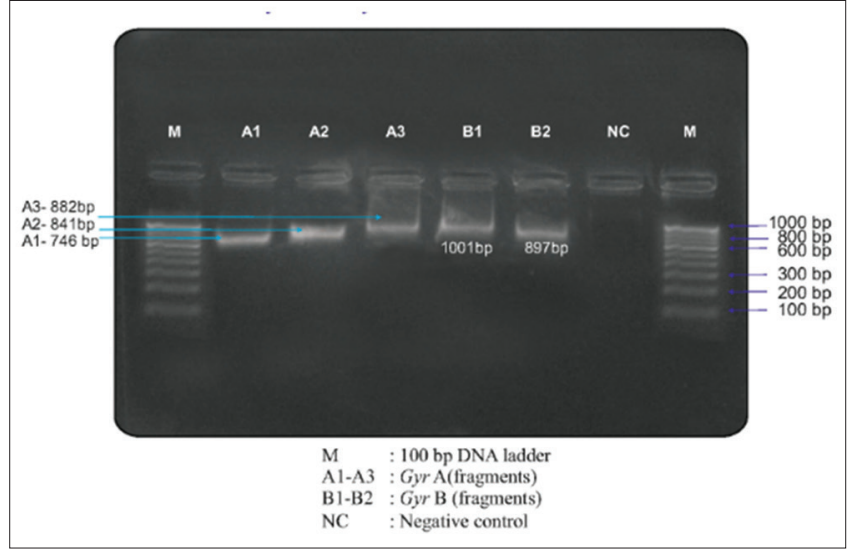

Fig. 5: Polymerase chain reaction amplification of Gyr $A$ and Gyr B gene

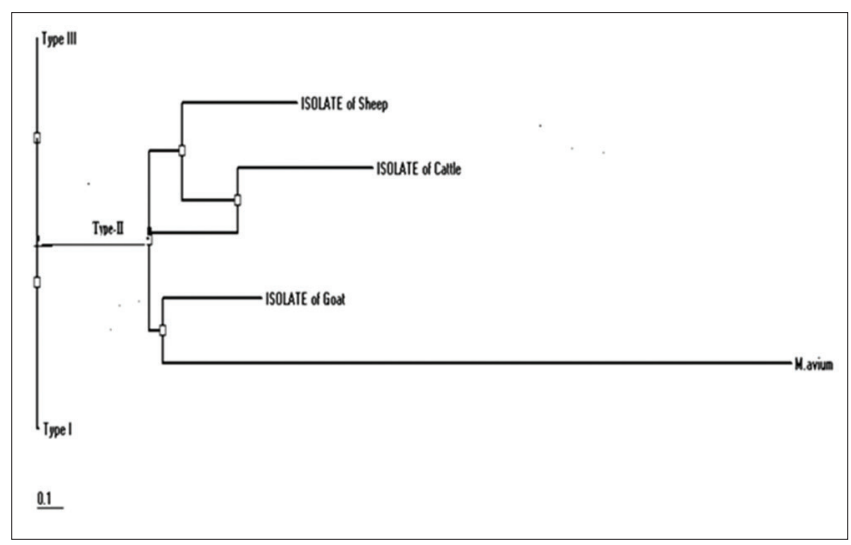

Fig. 6: Phylogenetic tree of Gyr A gene of MAP isolates

methods. Before taking up the study, the isolates were identified by PCR by IS900 PCR as per Vansnick et al. [7], who reported that IS900 PCR accurately identified MAP isolates and also stated that primers used targeted specific regions of IS900 avoiding overlapping IS1626 fragments and false positive results in PCR. Further, all the isolates were confirmed by F57 PCR on the lines suggested by Vansnick et al. [7], who reported that F57 PCR would be used as complimentary to IS900 PCR for identification of MAP, as the F57 gene is sub species specific with a single copy in MAP [9]. The F57genome had no homology with known MAP and non-MAP sequences thereby confirmation of isolates by F57 PCR reduce the non-specificity associated with IS elements like IS900.

The MAP strains are classified into three groups, namely, cattle, sheep, and intermediate types based on restriction fragment length polymorphism analysis [10]. It is very well-established fact that transposable insertion elements randomly occupied multiple sites into the genome in a defined pattern and these insertions were sufficiently stable to be exploited as genetic markers to discriminate different strains of MAP. de Juan et al.(2006) [11] suggested PCR-based techniques could classify the MAP strains into two main groups that would correspond with the cattle or Type II and sheep or Type I/III.

A total of 22 MAP isolates originated from cattle, sheep, and goats showed amplicons of specific to IS1311 and generated bands specific for Intermediate type of MAP on Hinf1 and Mse1 digestion of IS1311 PCR products. The IS1311 PCR with REA that targeted a point mutation in the IS1311 sequence, which enabled distinction of MAP isolates from sheep and cattle. The restriction pattern generated on digestion with Hinf1 was due to the presence of a cytosine to thymidine (C to T) mutation at position 223 in all the copies of IS1311 in bison

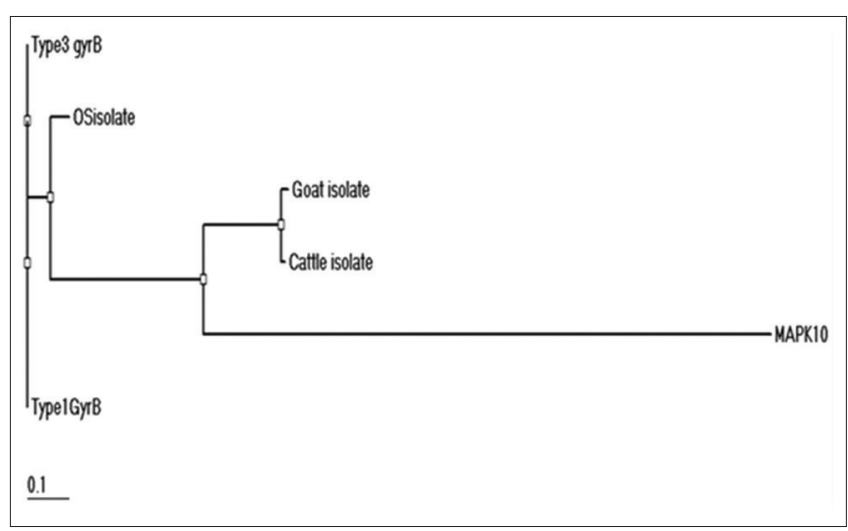

Fig. 7: Phylogenetic tree of GyrB gene of Mycobacterium avium subsp. paratuberculosis isolates

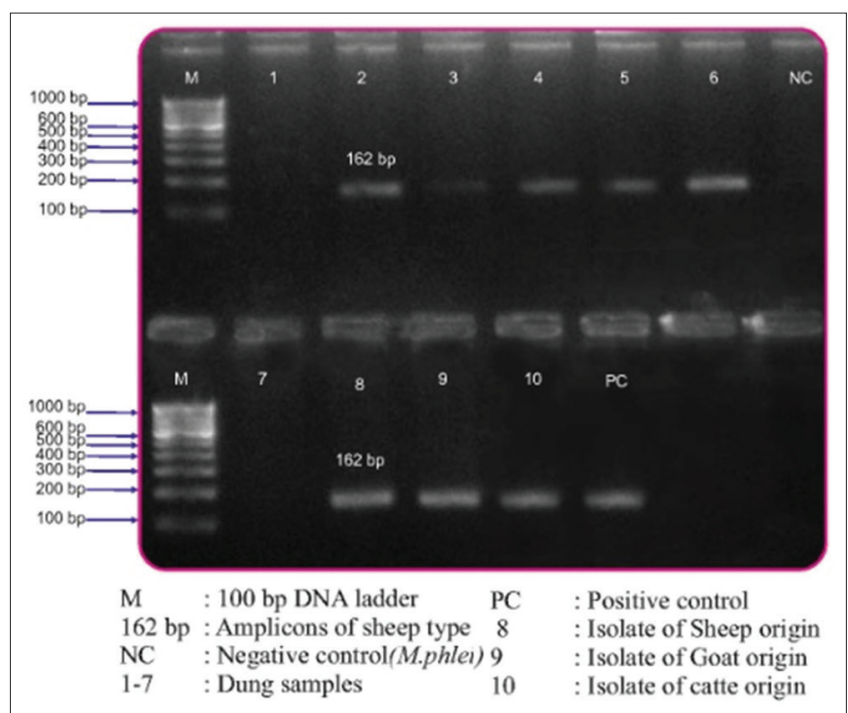

Fig. 8: Amplicons of digital microfluidic chip polymerase chain reaction of Mycobacterium avium subsp. paratuberculosis isolates

type or Intermediate type of MAP. In this study, the isolates generated a banding pattern similar to Intermediate type of MAP. The findings are also in conformity with the interpretation of Sohal et al. 2009, [12] who reported that all Indian isolates from sheep and goats belonged to bison type and also stated that even though Indian isolates belonged to "Bison type", they were different from all other types prevalent elsewhere, and belonged to new biotype. The differences in cattle type and sheep type strains were due to adaptation to respective preferred host. They also reported predictable geographical differences in MAP isolates between continents and different regions and such deviations any from cattle or sheep types were considered as Intermediate type.

All the MAP isolates studied shown a similar pattern as Intermediate type, but not exhibited any designated cattle type or sheep type pattern. Juan et al. (2005), who have reported the presence of Type I/III MAP in cows and goats other than cattle type from Spain [11]. Interpretations of the results obtained in the study are in accordance with the findings of Whittington et al. (2000), who identified distinct lineage of MAP isolates as intermediate type [13]. The molecular typing of 60 MAP isolates from a different host and geographical origin including India by IS1311 PCR-REA assay and reported the prevalence of bison type of MAP in India irrespective of their host and geographical location.

Sequence analysis of partial nucleotide sequences of IS1311-PCR products was analyzed for polymorphism in RE sites using the online software NEB cutter. The IS1311 PCR products sequence showed the 
MAP specific restriction enzyme Hinf1 sites and the BSJ1 site, which is specific for Indian Bison type.

Castellanos et al. (2007) found conserved SNPs within gyr $A$ and $B$ genes and developed PCR targeting the specific variable areas to differentiate three type strains of MAP as Type I, II, and III isolates, which was not possible with other technique like IS1311 PCR with REA [14]. 22 MAP isolates in this study originated from cattle, sheep, and goats showed amplicons of specific to GyrA and GyrB PCR and generated bands specific for Intermediate type of MAP. Partial nucleotide sequences obtained from amplicons of gyrA and gyrB PCR of MAP isolates were analyzed and by blast search in NCBI GenBank with available nucleotide database of reference MAP type strains and other mycobacterial type strains and found 94-99\% identity with the sequences of known Type III or Type I isolates of MAP, respectively. Sequences were showing clear differentiation with the M. avium avium and other mycobacteria like Mycobacterium tuberculosis.

The multiple sequence alignments generated for nucleotide sequences of gyrA and gyrB genes of selected MAP isolates from cattle, sheep, and goat with the sequences of reference MAP Types I, III and Type II (MAP-K10) isolates and other mycobacterial isolates using ClustalW found the MAP isolates are showing more lineage toward the Type III of MAP irrespective of their host species of origin.

These findings are in correlation with the de Juan et al. (2006), who proposed Type I/III and II based on PCR-based techniques and reported the high prevalence of Type I/III in cattle (29/52) and goats $(20 / 52)$ in Spain [11]. Between the isolates, the sequences from cattle and goat isolates align more closely. The sequences obtained from isolate of sheep origin aligned closely with the sequences of S strain of MAP, which was in conformity with de Juan et al. (2006) who reported the Type III strains were more similar to Type I than Type II strains when analyzed by molecular techniques and growth characteristics [11]. The heterogeneity displayed among isolates could be due to host-pathogen interaction, specificity of the strains or pathogen adaptation to the environmental factors as described by de Juan et al. (2006) [11]. Since nucleotide sequencing carried out in the study was from variable regions gyrA and gyrB genes, full-length sequencing of genes may provide more insight than partial gene sequence.

Amplification of 5 end of IS900 of MAP isolates by DMC-PCR revealed amplicons of $162 \mathrm{bp}$ indicating that all the isolates belonged to the sheep lineage of MAP irrespective of the host of origin. The results are also in agreement with Collins et al. (2002), who developed DMCPCR and differentiated MAP isolates into cattle type or sheep type and reported that non-MAP isolates did not get amplified in PCR [15]. The observations are also correlated with de Juan et al. (2006), who categorized 158 MAP isolates of Spain origin into sheep type and cattle type by DMC-PCR and reported the prevalence (52/158) of Type I/III isolates in sheep, goat, and cattle [11]. They also stated that the isolates which were closely related to or originated from sheep strain would generate band specific to sheep type by DMC-PCR.

Results from this study confirmed that all the isolates studied were Type III or intermediate type, which were closely related to Type I isolates and generated band specific to sheep type irrespective of host from which sample was originated. The DMC-PCR is advantageous as it can identify MAP and also give some information about the molecular type of MAP without REA or sequencing and comparatively better than regular IS900 PCR, which can identify the MAP but does not give any information about the type of MAP. However, DMC-PCR has the limitation that it could not discriminate Type I or Type III strains separately, which is closely related genetically.

Amplification of 5 end of IS900 of MAP isolates by DMC primers revealed amplicons of $162 \mathrm{bp}$ indicating that all the isolates belonged to the sheep lineage of MAP irrespective of the host of origin. The results are also in agreement with Collins et al. (2002) [15], who developed DMC-PCR and differentiated MAP isolates into cattle type or sheep type and reported that non-MAP isolates did not get amplified in PCR.

\section{CONCLUSION}

This study which has been undertaken with the objective of molecular characterization of prevalent MAP isolates from cattle, sheep, and goat demonstrated that IS1311 PCR with REA, which is based on point mutations in the IS1311, identified all 24 MAP isolates as 'Intermediate type' irrespective of host of origin. Sequence analysis of partially amplified IS1311 using online NIB cutter software showed MAP specific Hinf1 site and Indian MAP isolates specific BSJ1 site. Molecular typing based on the gyrA and gyrB genes partial amplification and sequencing revealed, that the MAP isolates exhibited more lineage toward the reference Type III, which is an Intermediate strain. The MAP isolate of sheep origin showed more lineage toward the sheep type than the isolates of cattle and goats. This variation may be due to host-pathogen interactions and adaptation to different hosts and conditions in nature. The DMC-PCR, which is based on sequence difference at $5{ }^{\circ}$ end of IS900 of MAP, differentiated rapidly all the isolates as sheep type. The inability of DMC-PCR to differentiate sheep and Intermediate type separately was found to be the limitation of this method. Since the Intermediate type (Type III) and sheep type (Type I) are very closely related to each other, all the isolates were identified as sheep type by DMC-PCR. All the MAP isolates are confirmed as Intermediate or Type III, which are common in India, Spain, and Iceland.

\section{ACKNOWLEDGMENTS}

Thanks are due to the University authorities and the Director, Institute of Animal Health and Veterinary Biologicals (IAH\&VB), Hebbal, Bangalore, KVAFSU for granting study leave to carry out this work.

\section{REFERENCES}

1. Sweeney RW. Transmission of paratuberculosis. Vet Clin North Am Food Anim Pract 1996;12:305-12.

2. Ott SL, Wells SJ, Wagner BA. Herd-level economic losses associated with Johne's disease on US dairy operations. Prev Vet Med 1999;40(3-4):179-92.

3. Nielsen SS, Grønbaek C, Agger JF, Houe H. Maximum-likelihood estimation of sensitivity and specificity of ELISAs and faecal culture for diagnosis of paratuberculosis. Prev Vet Med 2002;53(3):191-204.

4. Green EP, Tizard ML, Moss MT, Thompson J, Winterbourne DJ, McFadden JJ, et al. Sequence and characteristics of IS900, an insertion element identified in a human Crohn's disease isolate of Mycobacterium paratuberculosis. Nucleic Acids Res 1989; 17(22):9063-73.

5. Motiwala AS, Li L, Kapur V, Sreevatsan S. Current understanding of the genetic diversity of Mycobacterium avium subsp. paratuberculosis. Microbes Infect 2006;8(5):1406-18.

6. Reddy YG, Prakash R, Anandakumar S. Isolation, cloning and expression of recombinant staphylokinase gene against thrombosis. Int J Pharm Pharm Sci 2014;6(4):266-70.

7. Vansnick EL, de Rijk OP, Vercammen F, Geysen D, Rigouts L, Portaels F. Newly developed primers for the detection of Mycobacterium avium subsp. paratuberculosis. Vet Microbiol 2004;100:197-204.

8. Nath SS. Serological immune diagnosis of tuberculosis using PCR and in-house developed clinical isolate based ELISA. Int J Pharm Pharm Sci 2013;5(3):584-92.

9. Poupart P, Coene M, Van Heuverswyn H, Cocito C. Preparation of a specific RNA probe for detection of Mycobacterium paratuberculosis and diagnosis of Johne's disease. J Clin Microbiol 1993;31(6):1601-5.

10. Pavlik I, Horvathova A, Dvorska L, Bartl J, Svastova P, du Maine R, et al. Standardisation of restriction fragment length polymorphism analysis for Mycobacterium avium subspecies paratuberculosis. J Microbiol Methods 1999;38(1-2):155-67.

11. de Juan L, Alvarez J, Aranaz A, Rodríguez A, Romero B, Bezos J, et al. Molecular epidemiology of Types I/III strains of Mycobacterium avium subspecies paratuberculosis isolated from goats and cattle. Vet Microbiol 2006;115(1-3):102-10.

12. Sohal JS, Singh SV, Subodh S, Sheoran N, Narayanasamy K, Singh PK, et al. Mycobacterium avium subspecies paratuberculosis diagnosis and 
geno-typing: Genomic insights. Microbiol Res 2009;164(3):330-7.

13. Whittington RJ, Hope AF, Marshall DJ, Taragel CA, Marsh I. Molecular epidemiology of Mycobacterium avium subsp. paratuberculosis: IS900 restriction fragment length polymorphism and IS1311 polymorphism analyses of isolates from animals and a human in Australia. J Clin Microbiol 2000;38(9):3240-8.

14. Castellanos E, Aranaz A, Romero B, de Juan L, Alvarez J, Bezos J, et al.
Polymorphisms in gyrA and gyrB genes among Mycobacterium avium subsp. paratuberculosis type I, II and III isolates. J Clin Microbiol 2007;45(10):3439-42.

15. Collins DM, Zoete MD, Cavaignac SM. Mycobacterium avium subsp. paratuberculosis strains from cattle and sheep can be distinguished by a PCR test based on a Novel DNA sequence difference. J Clin Microbiol 2002;40(12):4760-2. 